\title{
Avaliação dos níveis de frutosamina em gatos sob estresse agudo e crônico
}

\author{
Assessment of fructosamine concentrations in cats with acute and chronic stress
}

\author{
Lívia Fagundes MORAES ${ }^{1}$; Camila Martos THOMAZINI루 Regina Kiomi TAKAHIRA ${ }^{1}$; Lídia Raquel \\ de CARVALHO ${ }^{2}$ \\ ${ }^{1}$ Laboratório Clínico Veterinário do Departamento de Clínica Veterinária da Faculdade de Medicina Veterinária e Zootecnia da \\ Universidade Estadual Paulista, Botucatu - SP, Brasil \\ ${ }^{2}$ Departamento de Bioestatística do Instituto de Biologia da Universidade Estadual Paulista, Botucatu - SP, Brasil
}

\begin{abstract}
Resumo
Frutosaminas são proteínas séricas glicadas formadas continuamente resultantes da ligação entre a glicose e proteínas circulantes, e correspondem à avaliação glicêmica de aproximadamente uma a duas semanas em gatos. A concentração de frutosamina tem sido utilizada para a diferenciação entre a hiperglicemia persistente e transitória induzida pelo estresse, sendo considerado o teste padrão ouro para o controle da glicemia em gatos diabéticos. O objetivo deste trabalho consistiu em avaliar a influência dos estados de estresse agudo e crônico em gatos sobre os níveis séricos de frutosamina. Foram selecionados 62 felinos provenientes do atendimento no Hospital Veterinário da FMVZ - UNESP Botucatu, distribuídos em três grupos: felinos com histórico de qualquer doença ou condições de estresse, excluindose o diabetes mellitus (DM), por um período máximo de 48 horas (Grupo $\mathrm{A}, \mathrm{n}=21$ ) ou por um período superior a 120 horas (Grupo B, $n=27$ ). O terceiro grupo (Grupo $\mathrm{C}=$ controle) foi formado por 14 felinos saudáveis. Os grupos foram avaliados quanto às dosagens séricas de frutosamina, glicose, proteína e albumina. Foi constatado um aumento significativo nos valores de frutosamina tanto nos animais submetidos ao estresse agudo quanto crônico, porém os níveis mantiveram-se dentro do intervalo de referência. Da mesma forma, os animais, em média, também se encontravam em normoglicemia, apesar da correlação positiva entre as concentrações de glicose e frutosamina. Conclui-se que a concentração de frutosamina sofre influência dos estados de estresse agudo e crônico em gatos, mantendo-se, porém, dentro dos limites de referência, sendo, portanto, útil no diagnóstico do DM.
\end{abstract}

Palavras-chave: Frutosamina. Gato. Estresse. Glicemia.

\begin{abstract}
Fructosamine are glycated serum proteins that are formed continuously due to the reaction between glucose and circulating proteins, and corresponding to the blood glucose control assessment over the last one to two weeks in cats. The fructosamine concentration has been used for differentiation between persistent and transient hyperglycemia. Therefore, the determination of fructosamine is considered the gold standard for monitoring glycemia into control in diabetic cats. The objective of this study was to evaluate the influence of acute and chronic stress of cats on serum fructosamine. 62 cats were selected from the Veterinary Hospital of FMVZ - UNESP, Botucatu campus. They were distributed into three groups: cats with a history of any illness or stress condition, excluding Diabetes Mellitus (DM), for a maximum of 48 hours (Group $A, n=21$ ) or for a period exceeding 120 hours (Group B $n=27$ ). The third group (Group $\mathrm{C}=$ control) was formed by 14 health cats. The groups were evaluated for serum fructosamine, glucose, protein and albumin. In this study, there was a significant increase in the values of fructosamine in animals subjected to acute and chronic stress, but these values remained within the reference range. The animals were, on average, normoglycemic, despite the positive correlation between fructosamine and glucose concentrations. We conclude that the fructosamine concentration is influenced by acute and chronic stress in cats, remaining, however, within the reference range, and therefore, still useful in the diagnosis of DM.
\end{abstract}

Keywords: Fructosamine. Cat. Stress. Glicemia.

Correspondência para:

Lívia Fagundes Moraes

Laboratório Clínico Veterinário

Departamento de Clínica Veterinária

Faculdade de Medicina Veterinária e Zootecnia

Universidade Estadual Paulista - UNESP
Distrito de Rubião Jr s/ nº Botucatu SP Brasil

CEP: 18618-970

e-mail: liviafm@gmail.com

Recebido: 07/12/2010

Aprovado: 05/10/2011 


\section{Introdução}

O Diabetes Mellitus (DM) é uma das endocrinopatias mais comuns em cães e gatos, sendo que os gatos tendem a apresentar a forma tida como tipo II ou não insulino-dependente da doença ${ }^{1,2}$.

O monitoramento glicêmico a longo prazo do DM pode ser realizado a partir da dosagem de frutosamina e da hemoglobina glicada ${ }^{2,3}$. Na tentativa de se avaliar a média glicêmica para o controle do diabetes em gatos, as concentrações séricas seriadas de frutosamina trazem informações mais valiosas quando comparadas com uma única dosagem de frutosamina ${ }^{4}$. As frutosaminas são proteínas séricas glicadas continuamente formadas, resultantes da ligação não enzimática, irreversível e insulino-independente entre a glicose e proteínas circulantes. Esta glicação é dependente da concentração sérica de glicose e proteínas, especialmente a albumina. Não se sabe ao certo a meia-vida das proteínas séricas em gatos, mas estima-se aproximadamente em uma a duas semanas, portanto acredita-se que este período corresponda à avaliação glicêmica do animal a partir dos valores de frutosamina ${ }^{5,6,7}$.

A concentração de frutosamina sérica aumenta quando não há um controle adequado da glicemia em gatos diabéticos e diminui quando se melhora o controle glicêmico. Portanto, a mensuração da frutosamina é considerada o teste padrão ouro para a avaliação da glicemia em gatos diabéticos ${ }^{8}$. A frutosamina é um parâmetro válido para o diagnóstico e controle metabólico do DM em cães e gatos, avaliando-se a adequação da insulinoterapia ${ }^{9}$. Gatos hiperglicêmicos que apresentam valores de frutosamina normais provavelmente possuem uma hiperglicemia transitória induzida por estresse ou uma hiperglicemia persistente de pequena duração ou severidade, insuficientemente capaz de levar a alterações nas concentrações de frutosamina ${ }^{9,10}$.

A hiperglicemia induzida pelo estresse resulta em imprecisão no diagnóstico do DM por meio da con- centração de glicose sérica; portanto a dosagem de hemoglobina glicada e de frutosamina auxiliam no diagnóstico inicial do $\mathrm{DM}$, principalmente em gatos, já que estas não sofrem interferência do estresse em seus valores ${ }^{3,11}$. Desta forma, a concentração sérica de frutosamina é utilizada para a diferenciação entre diabetes e hiperglicemia por estresse e para avaliação do controle metabólico de gatos diabéticos em tratamento ${ }^{12}$. Estudos mais recentes tem sido realizados na tentativa em se definir a real interferência da hiperglicemia não diabética nos valores de frutosamina ${ }^{4,10,12,13}$.

Algumas condições clínicas são responsáveis por um resultado falsamente diminuído dos valores de frutosamina em gatos como o hipertireiodismo e a hipoproteinemia intensa ${ }^{7,10,14}$. A dosagem de frutosamina em felinos hipertireoideos pode ser de difícil interpretação quando a mesma é utilizada para controle glicêmico em animais diabéticos, até mesmo após o início do tratamento para hipertireoidismo ${ }^{14}$. No estudo de Reusch e Tomsa ${ }^{15}$, os valores de frutosamina permaneceram significativamente abaixo do intervalo de referência tanto em animais normoproteicos quanto nos hipoproteicos, concluindo que a frutosamina não deve ser utilizada como ferramenta diagnóstica de DM ou hiperglicemia por estresse em gatos hipertiroideos.

No estudo de Graham, Mooney e Murray ${ }^{14}$, os animais hipertireoideos que responderam drasticamente ao tratamento com terapia com iodo radioativo apresentaram um aumento nos valores de frutosamina, que pode ser atribuído à normalização do balanço das proteínas. As hipoproteinemias são responsáveis pelas alterações mais frequentes e pronunciadas nos níveis de frutosamina, acarretando em valores duvi$\operatorname{dosos}^{7,10}$. Cães com hipoalbuminemia e/ou hipoproteinemia apresentam valores de frutosamina inferiores aos valores de referência, diferentemente dos gatos que sofrem influência apenas em casos de hipoproteinemia. Esta diferença sugere que diferentes classes de proteínas podem ser glicadas em cães e gatos. Em 
cães a glicose provavelmente se liga primariamente à albumina e nos gatos esta ligação está mais associada às globulinas ${ }^{7}$.

Falsos aumentos nos valores de frutosamina também podem ser encontrados em amostras lipêmicas, hemolisadas e ictéricas ${ }^{16}$.

O metabolismo da glicose nos eritrócitos é insulino-independente, portanto, a extensão da glicação da hemoglobina reflete diretamente o grau de hiperglicemia $^{3}$. A hemoglobina glicada é menos efetiva para o monitoramento do diabetes em gatos devido à baixa permeabilidade à glicose e menor meia-vida das hemácias dos felinos, quando comparada aos cães ${ }^{17}$. Entretanto, outros estudos afirmam que esta técnica é um indicador real da glicemia em longo prazo; ou por um período um pouco maior do que a frutosamina ${ }^{6,18}$.

O objetivo deste trabalho consistiu em avaliar a relação entre os níveis de frutosamina nos estados de estresse agudo e crônico em gatos, buscando avaliar uma possível relação com a duração da condição de estresse.

\section{Material e Método}

Foram selecionados 62 felinos provenientes do atendimento no Hospital Veterinário da Faculdade de Medicina Veterinária e Zootecnia da Universidade Estadual Paulista "Júlio de Mesquita Filho" - FMVZ UNESP campus de Botucatu - São Paulo, distribuídos em três grupos: felinos com histórico de qualquer doença ou condições de estresse, excluindo-se o diabetes mellitus (histórico, avaliação clínica e exame de urina) por um período máximo de 48 horas (Grupo A, n $=21$ ) ou por um período superior a 120 horas (Grupo $\mathrm{B}, \mathrm{n}=27)$. O terceiro grupo (Grupo $\mathrm{C}=$ controle) foi formado por 14 felinos saudáveis. Foram coletados dados referentes ao tipo e período de evolução clínica da doença. Todos os animais selecionados foram avaliados quanto às dosagens séricas de frutosamina pelo método cinético de tempo fixo (Frutosamina Ref. 97-6/15; Labtest ${ }^{\oplus}$ Diagnóstica S.A., Lagoa Santa
- MG Brasil) e de glicose, proteína e albumina pelo método colorimétrico (Glicose CAT no 02200; Protal CAT no 03800 e Albumina CAT no 03900, respectivamente. Laborlab ${ }^{\oplus}$, produtos para laboratórios Ltda, Guarulhos - SP Brasil).

A comparação estatística entre os grupos foi realizada por meio da análise de variância para delineamento inteiramente ao acaso, seguido do teste de Tukey, para comparação das médias, quando necessário. A correlação entre os valores de frutosamina e as concentrações de glicose, proteína total e albumina foi realizada pelo método de correlação de Pearson. Foi utilizado um nível de significância de 5\% para todas as análises.

\section{Resultados}

As médias e desvios-padrão das variáveis proteína total sérica, albumina, glicose e frutosamina estão ilustradas na tabela 1 .

Considerando-se os valores das dosagens da proteína total sérica e albumina houve diferença estatística apenas entre os dois grupos de gatos sob estresse, sendo menores no grupo A (estresse agudo). Entretanto, apesar desta diferença estatística, os valores médios permaneceram dentro do intervalo de referência ${ }^{19}$.

Já em relação aos valores médios de glicose não houve diferença estatística entre os grupos, permanecendo também dentro do intervalo de referência ${ }^{19}$, no entanto o grupo A (estresse agudo) apresentou valores maiores.

Os valores séricos da frutosamina apresentaram diferença estatística $(\mathrm{p}<0,05)$, quando foram comparados os grupos sob estresse com o grupo controle. Tanto o grupo do estresse agudo quanto o grupo do estresse crônico apresentaram médias superiores à média do grupo controle. Entretanto, não houve diferença estatística entre os dois grupos experimentais (Tabela 1). Apesar desta diferença estatística a média dos três grupos permaneceu dentro do intervalo de 
Tabela 1 -Médias, desvios-padrão, intervalos de referência e valores de p para as dosagens séricas de proteína, albumina, glicose e frutosamina, segundo o grupo - Botucatu - 2010

\begin{tabular}{cccccc}
\hline & \multicolumn{5}{c}{ Grupo } \\
\cline { 2 - 5 } Variável & $\begin{array}{c}\text { Estresse Agudo } \\
\text { (Grupo A) }\end{array}$ & $\begin{array}{c}\text { Estresse Crônico } \\
\text { (Grupo B) }\end{array}$ & $\begin{array}{c}\text { Controle } \\
(\text { GrupoC) }\end{array}$ & $\begin{array}{c}\text { Valor de } \\
\text { referência }{ }^{19}\end{array}$ & Valor de p \\
\hline Proteína $(\mathrm{g} / \mathrm{dL})$ & $5,7 \pm 0,9 \mathrm{~b}$ & $6,6 \pm 0,9 \mathrm{a}$ & $6,1 \pm 0,6 \mathrm{ab}$ & $5,4-7,8$ & 0,002 \\
Albumina $(\mathrm{g} / \mathrm{dL})$ & $2,9 \pm 0,4 \mathrm{~b}$ & $3,3 \pm 0,5 \mathrm{a}$ & $3,1 \pm 0,2 \mathrm{ab}$ & $2,1-3,3$ & $<0,001$ \\
Glicose $(\mathrm{g} / \mathrm{dL})$ & $96,7 \pm 57,5$ & $85,3 \pm 18,5$ & $67,4 \pm 10,8$ & $70-110$ & 0,07 \\
Frutosamina $(\mu \mathrm{mol} / \mathrm{L})$ & $218,3 \pm 22,5 \mathrm{a}$ & $215,5 \pm 38,6 \mathrm{a}$ & $188,0 \pm 24,3 \mathrm{~b}$ & $146-271^{5}$ & 0,012 \\
\hline
\end{tabular}

Médias seguidas de pelo menos uma letra em comum não diferem estatisticamente $(\mathrm{p}<0,05)$

referência ${ }^{11}$. Foi constatada uma correlação positiva $(\mathrm{p}<0,05: \mathrm{r}=0,31)$ apenas entre as concentrações de frutosamina e glicose.

As condições de estresse mais comuns incluíram: estresse pós-cirúrgico (castração), doenças do trato urinário inferior, doenças renais e doenças do trato digestório e respiratório (Tabela 2).

\section{Discussão e Conclusões}

No presente trabalho, um estresse agudo, de duração máxima de 48 horas, foi capaz de aumentar significativamente os valores de frutosamina, em contraposição com os achados de Lutz, Rand e Ryan ${ }^{10}$, que induziram o estresse agudo (90 minutos) em gatos saudáveis e não observaram aumento da concentração de frutosamina. Estes valores, porém, mantiveram-se ainda dentro do intervalo de referência, concordando com os resultados encontrados por Reusch et al. ${ }^{9}$ e Crenshaw et al. ${ }^{12}$. Este aumento, apesar de significativo, foi pouco expressivo e pode estar associado aos valores glicêmicos médios normais destes animais no momento da avaliação. Este comportamento é esperado visto que houve uma correlação positiva significativa entre as concentrações de glicose e frutosamina. Correlação semelhante também foi detectada por Lutz, Rand e Ryan ${ }^{10}$, tanto em gatos diabéticos quanto em casos de hiperglicemia por estresse. (grupo de gatos doentes com hiper e normoglicemia).
Entretanto, no trabalho de Crenshaw et al. ${ }^{12}$ não se observou correlação entre os valores da frutosamina e glicose séricas no grupo de animais com hiperglicemia por estresse. Houve correlação $(r=0,7 ; n=100$; $\mathrm{p}<0,001)$ apenas quando os valores foram analisados como um único grupo (saudáveis, DM sem tratamento, DM durante tratamento e hiperglicemia por stress), com valores ainda maiores quando se excluiu os animais com hiperglicemia por estresse.

Estes autores relataram que o aumento da frutosamina associado ao estresse apresenta magnitude inferior ao observado em felinos diabéticos ${ }^{12}$. O estresse crônico (superior a cinco dias) também demonstrou influência sobre os valores de frutosamina, entretanto estes animais, em média, também não apresentaram hiperglicemia, não devendo representar uma dificuldade na diferenciação de um possível DM. Este aumento da concentração sérica de frutosamina também se manteve dentro do intervalo de referência, como encontrado em estudos anteriores ${ }^{4,10,12,16}$.

Não houve diferença estatística entre os dois períodos de estresse definido pelo presente estudo.

A influência do estresse sobre a frutosamina observada no presente estudo corrobora com a ideia de que a interpretação de seus valores deve ser cautelosa nos casos de DM recentemente diagnosticados e em casos de estresse prolongado 9 . Entretanto, outros estudos afirmam que mesmo em casos de hiperglicemia associados a estresse prolongado, o aumento de frutosa- 
Tabela 2 - Porcentagem de ocorrência das condições de estresse em relação ao período avaliado, segundo os grupos - Botucatu - 2010

\begin{tabular}{lccc}
\hline Condição de estresse & $\begin{array}{c}\text { Estresse Agudo } \\
\text { até } 48 \text { horas } \\
\text { (Grupo A) }\end{array}$ & $\begin{array}{c}\text { Estresse Crônico } \\
\text { superior a 120 horas } \\
\text { (Grupo B) }\end{array}$ & TOTAL \\
\hline Doença do trato urinário inferior & $04(18,2 \%)$ & $02(7,1 \%)$ & $06(12 \%)$ \\
Doenças renais & 00 & $04(14,3 \%)$ & $04(8 \%)$ \\
Doença do trato respiratório & 00 & $03(10,7 \%)$ & $03(6 \%)$ \\
Doença do trato digestório & $02(9,1 \%)$ & $02(7,1 \%)$ & $04(8 \%)$ \\
Estresse pós-cirúrgico (castração) & $13(59,2 \%)$ & $11(39,4 \%)$ & $24(48 \%)$ \\
Alterações neurológicas & $01(4,5 \%)$ & $01(3,6 \%)$ & $02(4 \%)$ \\
FelV & 00 & $02(7,1 \%)$ & $02(4 \%)$ \\
Quilotórax & $01(4,5 \%)$ & 00 & $01(2 \%)$ \\
Hepatopatias & 00 & $02(7,1 \%)$ & $02(4 \%)$ \\
Alterações reprodutivas & $01(4,5 \%)$ & 00 & $01(2 \%)$ \\
Neoplasia (Carcinoma) & 00 & $01(3,6 \%)$ & $01(2 \%)$ \\
\hline
\end{tabular}

mina encontra-se em níveis inferiores se comparados com os casos de animais com DM recentemente diagnosticados ou com um controle glicêmico inadequa$\mathrm{do}^{12}$. Desta forma, a dosagem de frutosamina ainda é uma excelente ferramenta diagnóstica para o DM e para a diferenciação entre DM e uma hiperglicemia por estresse.

Em situações nas quais o diagnóstico do DM é incerto, assim como nos casos de hiperglicemia por estresse com glicemia moderada e glicosúria, a dosagem de frutosamina deve ser realizada. Além disso, a dosagem de frutosamina é uma técnica simples, acessível e barata, podendo ser incluída na rotina clínica para a investigação dos casos de hiperglicemia em gatos.

No estudo de Link e Rand ${ }^{4}$ as alterações acima dos valores de referência na concentração da frutosamina ocorreram após três a cinco dias de uma hiperglicemia crônica acentuada ( $540 \mathrm{mg} / \mathrm{dL}$ por 42 dias) e sete dias após uma hiperglicemia moderada $(310 \mathrm{mg} / \mathrm{dL}$ por 42 dias). Quanto maior o nível glicêmico, maior foi o período para que a frutosamina retornasse aos valores normais (seis dias), refletindo, portanto, a concentração de glicose da semana anterior. Um aumento moderado dos níveis de glicose pode levar a uma falha no diagnóstico do DM, nos casos em que é realizada apenas uma única mensuração da frutosamina, pois o aumento nos valores da frutosamina pode ser discreto e, portanto, deve ser diferenciado do estresse hiperglicêmico, a partir de dados clínicos e acompanhamento do caso. O grau de elevação e o momento no qual os valores de frutosamina excedem o intervalo de referência dependem da concentração de glicose e da duração da hiperglicemia ${ }^{4}$.

Neste estudo, não houve interferência dos valores de proteína total sérica e albumina na dosagem de frutosamina, pois os valores médios das mesmas encontraram-se dentro do intervalo de referência e não foi detectada correlação significativa entre suas concentrações e os níveis séricos de frutosamina.

Podemos concluir que gatos com níveis glicêmicos normais e submetidos tanto ao estresse agudo quanto crônico apresentam um aumento significativo, porém pouco expressivo, de frutosamina quando comparados a animais saudáveis. 


\section{Referências}

1.BENNETT, N. Monitoring techniques for diabetes mellitus in the dog and the cat. Clinical Techniques in Small animal Practice, v. 17, n. 2, p. 65-69, 2002.

2. RAND, J. S.; MARSHALL, R. D. Diabetes mellitus in cats. The Veterinary Clinics of North America: Small Animal Practice, v. 35, n. 1, p. 221-224, 2005.

3. MILLER, E. Long-term monitoring of the diabetic dog and cat. The Veterinary Clinics of North America: Small Animal Practice, v. 25, n. 3, p. 571-584, 1995.

4. LINK, K. R.; RAND, J. S. Changes in blood glucose concentration are associated with relatively rapid changes in circulating fructosamine concentrations in cats. Journal of Feline Medical Surgery, v. 10, n. 6, p. 583-592, 2008.

5. THORESEN, S. J.; BRENDAL, W. P. Determination of a reference range for fructosamine in feline serum samples. Veterinary Research Communications, v. 19, n. 5, p. 353$361,1995$.

6. ELLIOTT, D. A.; NELSON, R. W.; REUSCH, C. E.; FELDMAN, E. C.; NEAL, L. A. Comparison of serum fructosamine and blood glycosylated hemoglobin concentrations for assessment of glycemic control in cats with diabetes mellitus. Journal of the American Veterinay Medical Association, v. 214, n. 12, p. $1794-1798,1999$.

7. REUSCH, C. E.; HABERER, B. Evaluation of fructosamine in dogs and cats with hypo- or hyperproteinaemia, azotaemia, hyperlipidaemia and hyperbilirubinaemia. The Veterinary Record, v. 148, n. 12, p. 370-376, 2001.

8.MORI, A.; LEE, P.; MIZUTANI, H.; TAKAHASHI, T.; AZAKAMI, D.; MIZUKOSHI, M.; FUKUTA, H.; SAKUSABE, N.; SAKUSABE, A.; KIYOSAWA, Y.; ARAI, T.; SAKO, T. Serum glycated albumin as a glycemic control marker in diabetic cats. Journal of Veterinary Diagnostic Investigation, v. 21, n. 1, p. 112-116, 2009.

9. REUSCH, C. E.; LIEHS, M. R.; HOYER, M.; VOCHEZER, R. Fructosamine: a new parameter for diagnosis and metabolic control in diabetic dogs and cats. Journal of Veterinary Internal Medicine, v. 7, n. 3, p. 177-182, 1993.
10.LUTZ, T. A.; RAND, J. S.; RYAN E. Fructosamine concentrations in hyperglycemic cats. Canadian Veterinary Journal, v. 36, n. 3, p. 155-159, 1995.

11.THORESEN, S. I.; BREDAL, W. P. Clinical usefulness of measurements in diagnosing and monitoring feline diabetes mellitus. Journal of Small Animal Practice, v. 37, n. 2, p. 6468, 1996.

12.CRENSHAW, K. L.; PETERSON, M. E.; HEEB, L. A.; MOROFF, S. D.; NICHOLS, R. Serum fructosamine concentration as an index of glycemia in cats with diabetes mellitus and stress hyperglycemia. Journal of Veterinary Internal Medicine, v. 10, n. 6, p. 360-364, 1996

13.KAWAMOTO, M.; KANEKO, J. J.; HEUSNER, A. A.; FELDMAN, E. C.; KOIZUMI, I. Relation of fructosamine to serum protein, albumin, and glucose concentrations in healthy and diabetic dogs. American Journal of Veterinary Research, v. 53 , n. 5 , p. $851-855,1992$.

14.GRAHAM, P. A.; MOONEY, C. T.; MURRAY, M. Serum fructosamine concentrations in hyperthyroid cats. Research in Veterinary Science. v. 67, n. 2, p. 169-173, 1999.

15.REUSCH, C. E.; TOMSA, K. Serum fructosamine concentration in cats with overt hyperthyroidism. Journal of the American Veterinary Medical Association, v. 215, n. 9, p. 1297-1300, 1999.

16.PLIER, M. L.; GRINDEN, C. B.; MAC WILLIANS, P. S.; STEVENS, J. B. Serum fructosamine concentration in nondiabetic and diabetic cats. Veterinary Clinical Pathology, v. 27, n. 2, p. 34-39, 1998.

17.CHRISTOPHER, M. M. Hematologic complications of diabetes mellitus. The Veterinary Clinics of North America: Small Animal Practice, v. 25, n. 3, p. 625-637, 1995.

18.HOENIG, M.; FERGUSON, D. C. Diagnostic utility of glycosylated hemoglobin concentrations in the cat. Domestic Animal Endocrinology, v. 16, n. 1, p. 11-17, 1999.

19.KANEKO, J. J.; HARVEY, J. W.; BRUSS, M. L. Clinical biochemistry of domestic animals. 5th ed. San Diego, California: Academic Press, 1997. 932 p. 